\title{
Aplicação do Balanced Scorecard como Ferramenta de Gestão Estratégica em uma Empresa Transportadora de Cargas
}

\author{
Application of the Balanced Scorecard as a Strategic Management Tool in a Cargo Transport \\ Company
}

\author{
Gabriel Adam Bilato*a; Herlandí de Souza Andrade ${ }^{\mathrm{a}}$ \\ ${ }^{a}$ Universidade de São Paulo, Escola de Engenharia de Lorena. SP, Brasil. \\ *E-mail: gabrielbilato1993@gmail.com
}

\begin{abstract}
Resumo
O transporte rodoviário de cargas no Brasil é o mais importante dentre todos os modais, porém passou por uma grave crise devido ao recesso econômico que o país enfrentou nos últimos anos. Houve uma melhora do mercado nesse setor, porém muitas transportadoras ainda buscam se restabelecer em uma área na qual os custos são altos e a competitividade é grande. Nesse contexto e por meio de uma pesquisa ação, o objetivo geral desse estudo foi implementar a ferramenta de gestão estratégica Balanced Scorecard (BSC) em uma empresa deste setor e avaliar sua eficácia sobre a visualização do desempenho da companhia. O BSC foi aplicado por meio de uma metodologia que visou abranger tanto o cenário interno à empresa quanto externo, na qual extraiu-se os objetivos a partir de uma análise SWOT e assim criou-se os indicadores de desempenho. A implementação foi acompanhada a partir de uma base de dados referentes aos meses de setembro e outubro de 2019 para que fossem definidas as metas, e então analisou-se as possíveis melhorias para o scorecard. De forma geral, a execução da metodologia foi eficiente e o gestor avaliou satisfatoriamente a aplicação dos indicadores por meio da metodologia de gestão estratégica BSC e a nova maneira de visualizar o desempenho da companhia.
\end{abstract}

Palavras-chave: Transporte Rodoviário de Cargas. Gestão Estratégica. Balanced Scorecard. Análise SWOT.

\begin{abstract}
Road freight transport in Brazil is the most important of all modes, but it has gone through a crisis due to the economic recess that the country has faced in recent years. There has been an improvement in the market in this sector, but many carriers are still looking to reestablish themselves in a market where costs are high and competitiveness is high. In this context and through an action research, the general objective of this study was implementing the Balanced Scorecard (BSC) strategic management tool in a company of this sector and evaluate its effectiveness in visualizing the company's performance. The BSC was applied through a methodology that aimed to cover the internal and external scenarios, in which the objectives were extracted from a SWOT analysis and thus the performance indicators were created. The implementation was followed by a database for September and October 2019 to set goals and analyze possible improvements to the scorecard. Overall, the execution of the methodology was efficient and the manager evaluated satisfactorily the elaboration of the strategic planning and the new way of visualizing the company's performance.
\end{abstract}

Keywords: Road Freigh Transport. Strategic Management. Balanced Scorecard. SWOT Analysis.

\section{Introdução}

Com a globalização da economia, o mercado passou a depender não só do que cada empresa produz, mas, também, da disponibilidade de mão-de-obra qualificada e de matériaprima. Assim, há necessidade de uma melhor estruturação das empresas de logística e transporte, para atender a demanda do mercado atual. No Brasil, este assunto ganha relevância ainda maior, devido às grandes distâncias e o transporte rodoviário de cargas integrar toda a economia (LOBO; VALENTE, 2015).

Dentre as diversas formas de transporte (hidrovias, ferrovias, aéreo, entre outros) que o país apresenta, o rodoviário é o que merece maior destaque, pois representa $68,8 \%$ dos investimentos do governo federal e $63 \%$ de toda a logística brasileira. Por outro lado, é um setor que exibe diversos problemas, principalmente com relação à infraestrutura, impostos e, nos últimos anos, sofreu com a crise econômica com uma baixa no PIB do setor de 4,3\% em 2014 e 5,6\% em 2015. Os números de 2018 mostraram uma melhora de 1,7\% mesmo com a paralisação dos caminhoneiros, mas entre o período de 2015 e 2018 o crescimento ainda é negativo (CNT, 2018a).

A competitividade é outra questão que deve ser abordada. Atualmente, no Brasil há pouco mais de dois milhões e meio de caminhões e cerca de 158.168 empresas transportadoras de cargas que foram levantados pelo Instituto Brasileiro de Geografia e Estatística (IBGE) (CNT, 2018a). É importante ressaltar também os elevados custos para operar uma empresa desse ramo. Gastos com impostos, seguro contra roubo e responsabilidade civil e manutenção dos caminhões como pneus, lubrificantes e mecânica, geralmente demandam 
despesas e/ou custos altos. As atuais condições de infraestrutura das estradas brasileiras é também um dos motivos que aumentam os custos de operação de uma transportadora, pois o índice de avarias cresce e a vida útil do caminhão diminui. Além de tudo, deve ser levado em consideração a depreciação do caminhão e os custos do motorista durante o percurso da viagem.

Somando esses três fatores, a atual situação econômica do setor, a competitividade e os altos gastos para operar uma transportadora, mostra-se a necessidade de aplicar ferramentas de gestão estratégica, que auxilie os administradores de empresas transportadoras de carga a garantir maior planejamento quanto as tomadas de decisões, reduzir os índices de erros, diminuir os gastos, promover maior segurança durante o percurso e possibilitar o crescimento da companhia nesse mercado altamente competitivo.

Nesse contexto, o Balanced Scorecard (BSC) é uma alternativa de ferramenta para gestão estratégica, pois além de fazer uma análise financeira, pode-se avaliar a qualidade e o tempo de entrega ao cliente, verificar como estão os processos internos da companhia e levantar as inovações para manter a empresa competitiva no mercado (VACCARI, 2006).

É neste cenário que se encontra a empresa Transportadora Bilatto Ltda., objeto da pesquisa relatada neste artigo, que é uma empresa de pequeno porte, situada na cidade de Limeira (Estado de São Paulo), inserida no mercado de transporte de cargas há mais de 50 anos, atendendo, principalmente, o mercado de máquinas para beneficiamento de alimentos e transportando para todo o território brasileiro.

O objetivo deste artigo é demonstrar a aplicação de indicadores de desempenho em uma empresa de transporte rodoviário de carga, por meio da metodologia de gestão estratégica Balanced Scorecard (BSC).

\section{Material e Métodos}

O estudo seguiu as diretrizes de uma pesquisa-ação. Assim, o presente trabalho seguiu as quatro fases do ciclo básico da pesquisa-ação, conforme Tripp (2005), no qual foi feito um estudo sobre o tema proposto, baseado em uma revisão sistemática da literatura, e sobre esta, planejou-se os passos seguintes, ou seja, a ação foi tomada com a implementação da ferramenta estratégica estudada e monitorando os seus efeitos, e por fim, foi realizada a avaliação dos resultados e a melhoria foi proposta.

O estudo do projeto de implementação do BSC foi realizado na Transportadora Bilatto Ltda. A empresa que não possuía indicadores de desempenho implantados.

Para a construção de um plano estratégico foi necessário fazer uma extensa revisão da literatura, buscando as formas de implementar o BSC em empresas, guiando a sequência dos estudos para a continuação do trabalho. Ainda, para o desenvolvimento do trabalho foram realizadas diversas visitas na empresa, para reuniões com o gestor, foram conduzidas entrevistas abertas com funcionários de outras companhias do setor e foi feita uma visita à Feira Nacional dos Transportadores de Cargas (FENATRAN).

Desse modo, a metodologia para este trabalho seguiu as diretrizes de Levya, Rodriguez \& Fierro (2016), com pequenas adaptações. O fluxograma apresentado na Figura 1 mostra a sequência do trabalho para se alcançar os resultados.

Figura 1 - Fluxograma para desenvolvimento do trabalho

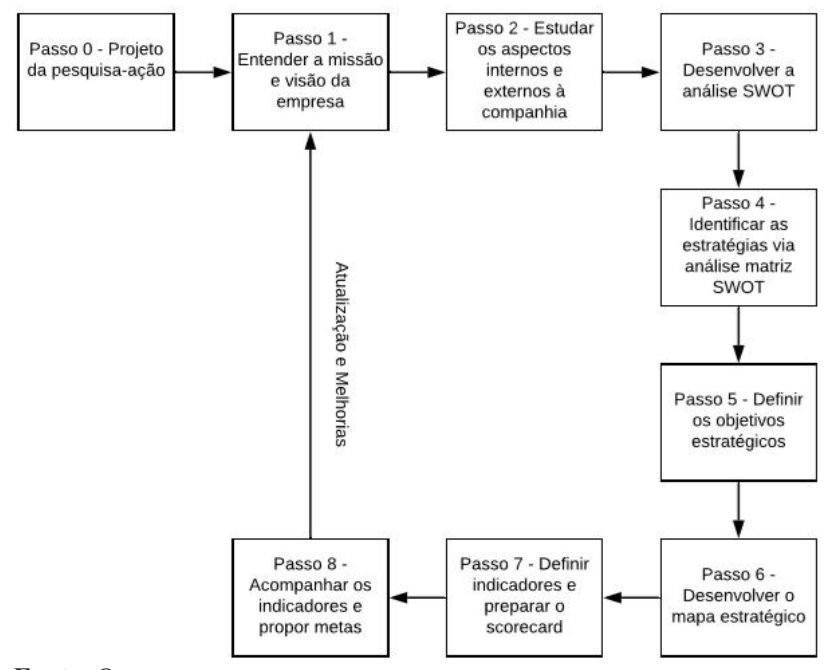

Fonte: Os autores.

No passo zero, que contemplou estudos sobre o tema, foram definidos os objetivos e elaboradas a metodologia que deveria ser seguida para alcançar os resultados. Em seguida, no passo um, foi analisada a empresa estudada, entendendo questões como missão, visão e valores. Para a definição desta primeira etapa foi necessário conhecer a percepção que os funcionários e o gestor têm da empresa por meio de entrevistas abertas. No passo dois foram avaliados aspectos como as forças e as fraquezas, por meio das análises dos dados existentes da empresa e foram validados os resultados das entrevistas feitas no passo anterior. Em seguida, a análise do setor de transportes de cargas foi realizada, com base em dados coletados pela rede e por meio de benchmarking com outras transportadoras, como forma de estudar as oportunidades e as ameaças. Além do estudo econômico, foi necessária uma avalição política (leis regulamentadas), sociocultural, tecnológica e infra estrutural do meio que a empresa está inserida. Tais análises foram fundamentais para iniciar o passo três, com a construção da análise SWOT, que foi feita para auxiliar na definição dos objetivos estratégicos. Assim, com as forças e fraquezas da organização, e as oportunidades e ameaças vistas pela ótica do mercado externo, no passo quatro foi possível extrair da análise SWOT informações necessárias para a identificação das estratégias em quatro diferentes dimensões: estratégias de desenvolvimento, estratégias de crescimento, estratégias de manutenção e estratégias de sobrevivência. Em seguida, no passo cinco priorizou-se a estratégia de acordo com os objetivos da companhia. Após definidas as estratégias que guiarão os planos da empresa, o passo seis foi realizado, 
com a criação do mapa estratégico determinando os objetivos para cada perspectiva proposta pelo BSC e interligando-os de acordo com a relação de causa e efeito entre eles. No passo sete, foram criados os indicadores, o scorecard foi preparado por meio de tabelas com o auxílio do software Excel e as metas foram definidas no passo oito por meio do acompanhamento dos indicadores, considerando a coleta dos dados existente entre os meses de setembro e outubro do ano de 2019. Ainda, no passo oito, foi possível, também, realizar uma análise da implementação do scorecard e verificar possíveis melhorias para os indicadores.

Dessa forma, por ser um estudo baseado em uma pesquisaação e de acordo com o resultado da implementação do BSC e dos feedbacks do gestor, foi proposto melhorias para o projeto apresentado e que poderá ser usado como um estudo futuro para que o ciclo continue conforme foi apresentado anteriormente.

\section{Resultados e Discussão}

\subsection{Balanced Scorecard - BSC}

Segundo Levya, Rodriguez e Fierro (2016) gestão estratégica é um conjunto de técnicas concentradas em avaliar os aspectos internos ao meio que está sendo avaliado, como também reconhecer a conjuntura externa em que atua, buscando orientar o desenvolvimento da estratégia a longo prazo de maneira objetiva. Pode-se dizer que gerir estrategicamente é uma maneira sistemática, contínua e dinâmica para que a companhia atinja seus objetivos estratégicos por meio de análises e tomadas de decisões.

Kaplan e Norton (1992) afirmam que grandes executivos entendem que medir o desempenho de suas organizações é extremamente necessário, pois o que não é medido não é gerenciado. Porém, percebeu-se que a maneira tradicional de apenas medir o desempenho financeiro da companhia não estava funcionando e verificou-se ser necessário indicadores balanceados entre a parte financeira e as operacionais. A metodologia BSC é uma ferramenta de planejamento estratégico que foi desenvolvida para eliminar essas limitações, abrangendo diversos cenários e perspectivas que a companhia estará sujeita, fazendo com que o desempenho financeiro seja apenas um resultado da performance desses outros cenários. Ao considerar todas as medidas importantes de uma vez, a administração pode detectar se uma área está melhorando às custas de outra (NACHTMANN et al., 2015). De forma complementarWiersma (2009) descreve que as empresas necessitam de sistemas de informações que meçam números em diferentes áreas e que auxiliem os administradores a tomar decisões de forma racional e assertiva, apoiando-os no direcionamento das atividades da companhia.

É importante ressaltar que ao utilizar o BSC é necessário que a visão, missão, estratégias e metas da organização estejam conectadas com as partes interessadas (Stakeholders), entre elas os clientes, empregados e fornecedores (DAVID, 1999; OLVE; ROY; WETTER, 2000; GRIGOROUDIS; ORFANOUDAKI; ZOPOUNIDIS, 2012).

Portanto entendeu-se que analisar os indicadores em diferentes perspectivas pode fornecer objetivos mais claros para avaliar os pontos mais críticos dos negócios. O BSC inclui quatro perspectivas de diferentes áreas, entre elas estão: financeiro, cliente, processos internos e inovação e aprendizagem. A análise dessas quatro diferentes áreas permite que a metodologia conecte o controle operacional de curto prazo com a visão e a estratégia, de longo prazo, de uma organização (KAPLAN; NORTON, 1992; KHOMBA, 2015).

O trabalho de Sadowska e Lulek (2016) mostra que para uma gestão eficiente no setor logístico é importante a utilização da ferramenta BSC, pois é necessário aliar a redução de custos, principal objetivo proposto, à um sistema que valorize clientes, qualidade de suas entregas e os processos internos. Então, foram sugeridos alguns objetivos a serem colocados em prática, em cada perspectiva, como mostra o Quadro 1.

Quadro 1 - Objetivos e exemplos de indicadores que podem ser utilizados na logística

\begin{tabular}{|c|l|l|}
\hline Perspectiva & \multicolumn{1}{|c|}{ Objetivos } & \multicolumn{1}{|c|}{ Exemplos de indicadores } \\
\hline Clientes & $\begin{array}{l}\text { - Oferecer serviços e produtos da melhor qualidade; } \\
\text { - Fortalecer laços entre empresa e cliente; } \\
\text { - Aumentar o nível de satisfação do cliente; } \\
\text { - Disponibilizar entrega de serviços e produtos em tempo } \\
\text { hábil. }\end{array}$ & $\begin{array}{l}\text { - Número de itens danificados em trânsito; } \\
\text { - Tempo de entrega dos produtos para o cliente. }\end{array}$ \\
\hline Financeiro & $\begin{array}{l}\text { - Usar os recursos financeiros de maneira eficaz; } \\
\text { - Implementar um plano financeiro; } \\
\text { - Envolver parceiros e fornecedores de serviços. }\end{array}$ & - Custos de transporte. \\
\hline $\begin{array}{c}\text { Processos } \\
\text { Internos }\end{array}$ & $\begin{array}{l}\text { - Melhorar o fluxo de informações; } \\
\text { - Criar confiança dentro da organização e condições favoráveis } \\
\text { de trabalho; } \\
\text { - Eliminar desperdícios. }\end{array}$ & $\begin{array}{l}\text { - Tempo de entrega de matéria-prima; } \\
\text { - Tempo de transferência de produtos acabados } \\
\text { da produção para o depósito; } \\
\text { - Controle de qualidade }\end{array}$ \\
\hline $\begin{array}{c}\text { Inovação e } \\
\text { aprendizado }\end{array}$ & $\begin{array}{l}\text { - Elevar as qualificações dos funcionários; } \\
\text { - Criar a lealdade e comprometimento dos funcionários; } \\
\text { - Flexibilizar a organização. }\end{array}$ & $\begin{array}{l}\text { - Número de treinamentos; } \\
\text { - Taxa de melhoria organizacional e técnica; } \\
\text { - Produtividade e envolvimento dos } \\
\text { colaboradores. }\end{array}$ \\
\hline
\end{tabular}

Fonte: Adaptado de Sadowska e Lulek (2016). 
A principal vantagem de utilizar-se de uma metodologia, como o BSC, para um gerenciamento estratégico de desempenho é o dinamismo. Outra grande vantagem é a interligação entre as quatro perspectivas, que permite a interrelação entre os indicadores com as estratégias do negócio, tornando a tomada de decisão mais assertiva (KAPLAN; NORTON, 1992; DAVID, 1999; OLVE; ROY;

\section{WETTER, 2000)}

David (1999) argumenta sobre a necessidade de conexão entre toda a cadeia do BSC para que a empresa obtenha sucesso na implementação da metodologia. Kaplan \& Norton (2008) desenvolveram um sistema de implementação do BSC que conecta o planejamento estratégico com a execução operacional e que está exemplificado conforme Figura 2.

Figura 2 - Sistema para implementação do Balanced Scorecard.

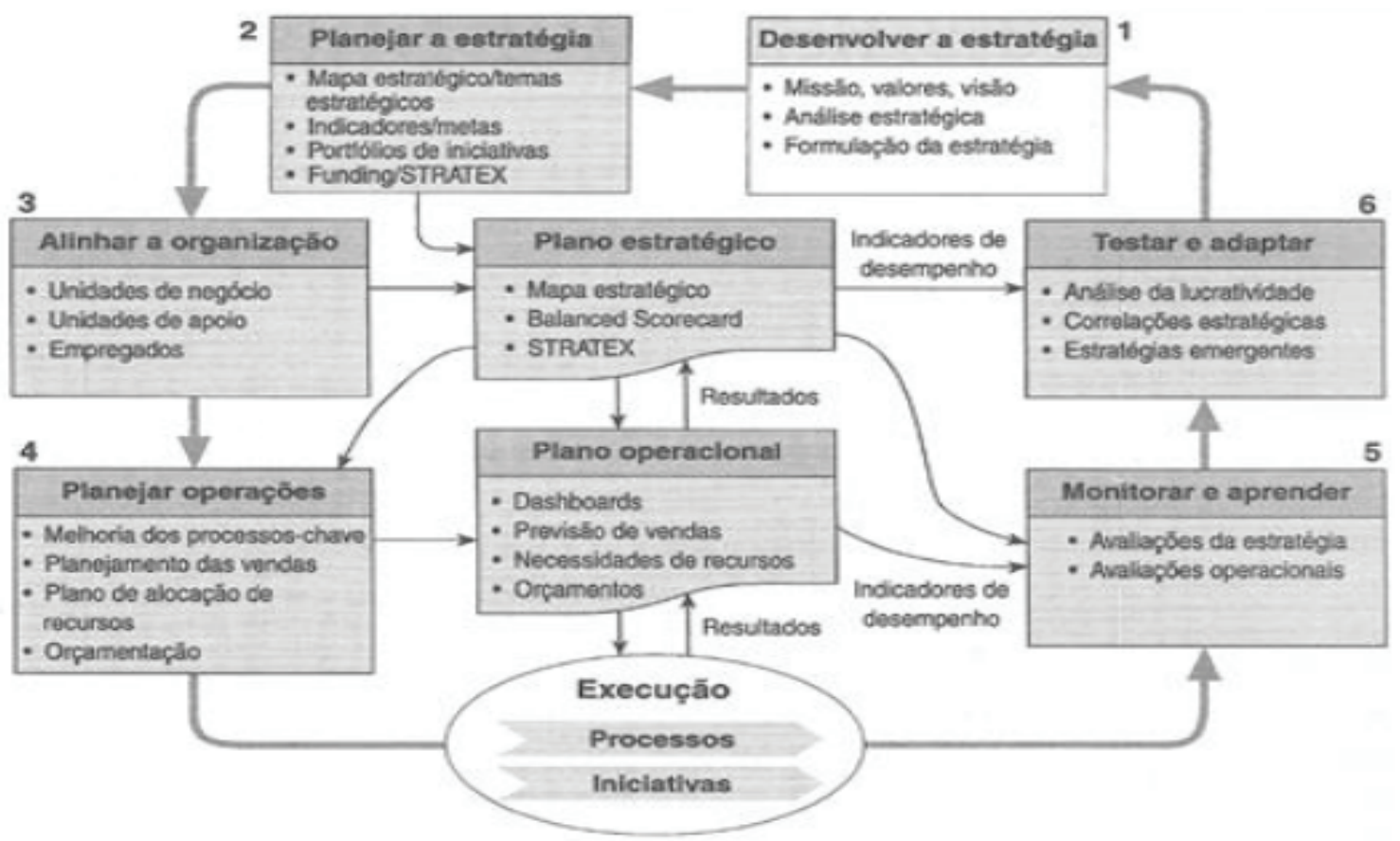

Fonte: Kaplan e Norton (2008).

O primeiro passo consiste em desenvolver a estratégia na qual será necessário entender o ambiente externo, interno e verificar a missão, visão, valores e os principais objetivos da organização (KAPLAN; NORTON, 2008).

Para analisar os aspectos externos, que podem interferir no andamento do desenvolvimento da estratégia, é necessário avaliar fatores como: político, econômico, sociocultural e tecnológico, e assim entender as oportunidades e as ameaças à instituição. Também é essencial estudar os aspectos internos à organização, como os recursos, as capacidades e as habilidades para que se possa entender as forças e as fraquezas da companhia. Juntos com as análises desses dois aspectos é possível se utilizar da ferramenta Análise SWOT (Strengths, Weaknesses, Opportunities, Threats) para identificar estratégias que possam trazer vantagens externas, erradicar as fraquezas e listar as forças, o que leva a uma melhor definição dos objetivos estratégicos (KHAKBAZ; HAJIHEYDARI, 2015; LEVYA; RODRIGUEZ; FIERRO, 2016).

O próximo passo é a definição dos objetivos estratégicos, indicadores, metas e orçamentos, que guiarão a organização nas próximas etapas. É proposto a criação de um mapa estratégico, semelhante ao exemplo da Figura 3, em que há uma melhor visualização dos objetivos definidos em perspectiva (KAPLAN; NORTON, 2008).

Figura 3 - Exemplificação de um mapa estratégico

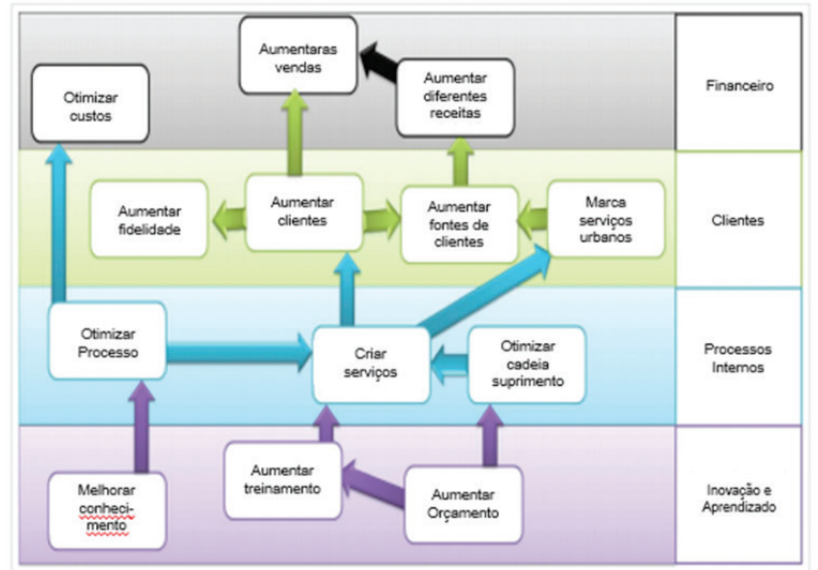

Fonte: Adaptado de Khakbaz e Hajiheydari (2015).

Um bom mapa estratégico deve ser simples, conectar os objetivos propostos para cada uma das quatro perspectivas, refletir graficamente as estratégias, mostrar claramente as relações de causa e efeito e facilitar a interpretação dos objetivos da organização (LEVYA; RODRIGUEZ; FIERRO, 
2016; CAMBOIM et al., 2017).

Jafari, Shahanaghi e Tootooni (2015) afirmam que as relações de causa e efeito, normalmente utilizadas para desenhar o mapa estratégico de uma companhia, são ambíguas e não levam em consideração as constantes mudanças que o atual mercado está sujeito, interferindo na estratégia da empresa. Por isso, propõe-se o conceito de mapa estratégico robusto no qual é avaliado o cenário do ambiente que a companhia está inserida.

Kaplan e Norton (2008) afirmam que, no terceiro passo a organização deve alinhar os funcionários sobre os objetivos e motivá-los a ajudar na continuidade para o sucesso das estratégias definidas pela companhia nos passos anteriores. Todos os participantes devem ser treinados para que conceitos da metodologia e os objetivos da companhia fiquem bem claros (KHOMBA, 2015; LEVYA; RODRIGUEZ; FIERRO, 2016).

A seguir, no passo quatro é preciso entender o objetivo mais crítico que possa impactar na execução da estratégia. Geralmente, o fluxo é desenhado tendo como foco objetivos da perspectiva financeira, como a produtividade e a redução de custos, enquanto outros estão relacionados a impactos sociais ou qualidade dos produtos entregues aos clientes. Este objetivo deve ser tratado como uma estratégia a longo prazo, mas que deve estar vinculado as operações diárias (curto prazo) (KAPLAN; NORTON, 2008).

Levya, Rodriguez e Fierro (2016) definem suas estratégias a longo prazo pelo que foi desenhado na análise SWOT, considerando quatro tipos de estratégias: ofensivas, defensivas, reorientação e sobrevivência.

Uma vez determinado, planejado e compreendido todo o plano estratégico, inicia-se o passo cinco, no qual a companhia começa a executá-lo e a monitorar os resultados de performance, para verificar o progresso ou as barreiras para a execução das estratégias. O acompanhamento dos resultados, em geral, ocorre em reuniões e nelas são tomadas decisões de curto prazo, como por exemplos ações para reclamações de clientes, quebras de máquinas e defeitos de processo.

$\mathrm{Na}$ sequência é necessário rever as constantes mudanças do mercado e entender se ainda continuam sendo pontos importantes para a estratégia da companhia, sendo esse o último passo para a implementação do BSC. A partir dessa etapa, quando é entendido que as estratégias não estão mais trazendo retorno a companhia, deve-se readaptar ou traçar novos planos, retornando ao primeiro passo e fechando o ciclo (KAPLAN; NORTON, 2008).

O modelo proposto por Kaplan e Norton (2008) foi sofrendo algumas modificações ao longo do tempo como forma de adequá-lo aos gaps que o método apresenta, ao mercado atual e ao interesse das empresas, incluindo modelos aplicados a diferentes setores da economia (SHARMA, 2007;
HUANG 2009; NACHTMANN et al., 2015; BHAGWAT; ANDRADE GUERRA et al., 2018).

Khakbaz e Hajiheydari (2015) propuseram um sistema, representado pela Figura 4, no qual será necessário técnicas mais sofisticadas, como simulação e modelagem, para analisar e entender os complexos sistemas dinâmicos de uma organização.

Figura 4 - Modelo adaptado do Balanced Scorecard

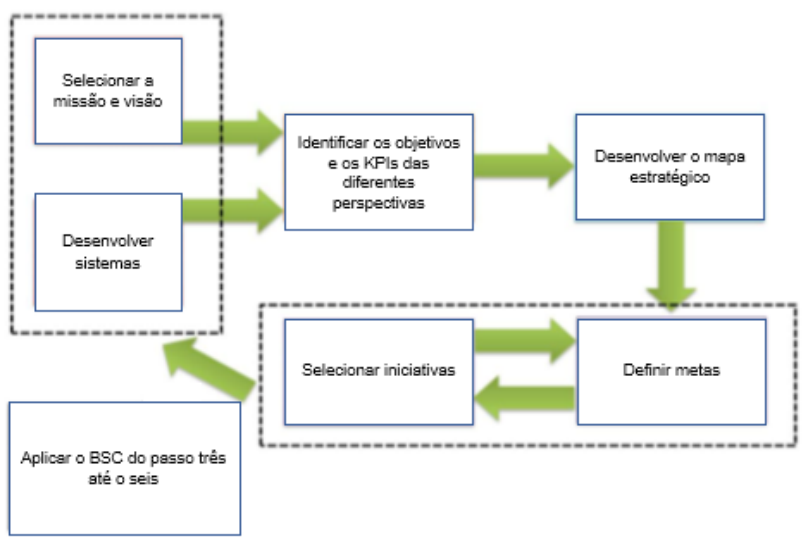

Fonte: Adaptado de Khakbaz e Hajiheydari (2015).

O primeiro passo dessa metodologia é entender a visão e a estratégia da companhia, algo semelhante ao que é proposto no BSC tradicional. A seguir é desenvolvido um sistema completo para a organização no qual estuda-se o ambiente interno através do modelo $7 \mathrm{~S}$ da Mckinsey e avalia-se o externo identificando aspectos como: políticos, econômicos, social, tecnológico, ambiental e judicial (KHAKBAZ; HAJIHEYDARI, 2015).

A metodologia proposta por Levya, Rodriguez e Fierro (2016), ilustrada pela Figura 5, foi dividida em 9 estágios. No desenvolvimento da filosofia organizacional é estudada a missão, visão e valores da organização. $\mathrm{Na}$ sequência, na segunda e na terceira fase são feitas as análises dos ambientes interno e externo, culminando na construção da análise SWOT, no passo quatro. A seguir, na etapa cinco é analisada a SWOT e identificada as estratégias a longo prazo que a empresa poderia seguir. Assim, na sexta e na sétima fase é definida uma lista com os objetivos a curto prazo com base no que foi determinado no passo anterior e então criado o mapa estratégico. Na etapa de número oito são criados os indicadores de desempenho com a definição das metas e dos intervalos de performance. Por fim, com base nos objetivos estratégicos e na filosofia da organização é possível definir uma lista de propostas de projetos para serem apresentados à alta gestão. 
Figura 5 - Metodologia proposta por Levya, Rodriguez \& Fierro (2016)

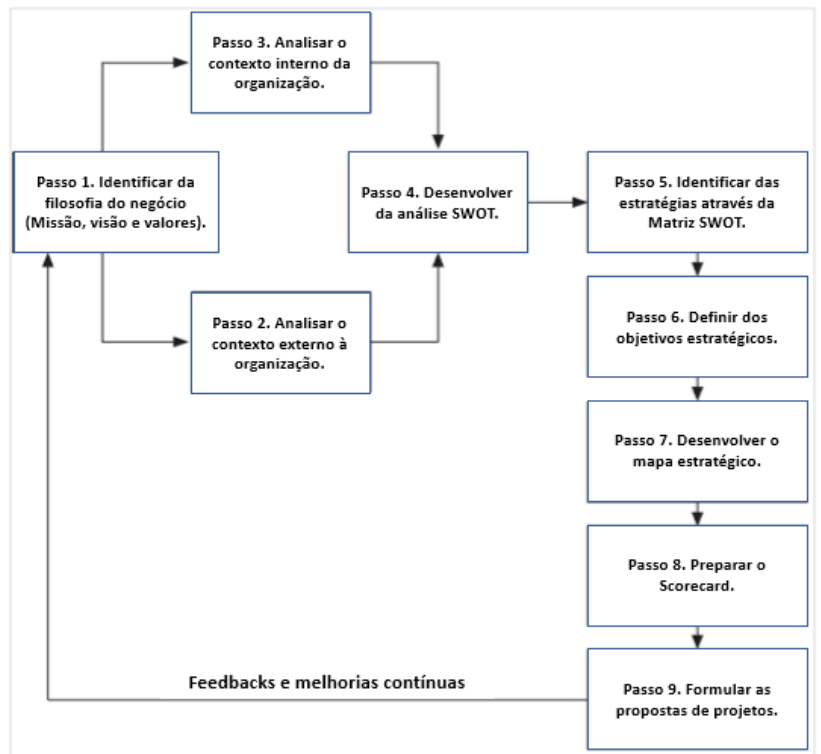

Fonte: Adaptado de Levya., Rodriguez e Fierro (2016).

\subsection{Análise SWOT}

A análise SWOT é uma técnica de planejamento estratégico usada em processos que exigem tomada de decisões e que permite fornecer informações sobre os ambientes externo e interno. O termo SWOT é derivado das iniciais das seguintes palavras em inglês: strengths (forças), weakness (fraquezas), opportunities (oportunidades) e threats (ameaças) (SILVA et al., 2011; CUI; ALLAN; LIN, 2019). É muito utilizada pelas empresas para difundir suas estratégias por meio do reconhecimento das limitações, maximizando as potencialidades e oportunidades, e monitorando as ameaças que podem derrubar todo o andamento da estratégia, ou seja, auxilia a empresa à tomar decisões, estruturar o planejamento estratégico e a se posicionar em relação ao mercado (SILVA et al., 2011; FERNANDES et al., 2015; BORGES RAUPP et al., 2019). A análise SWOT é exemplificada pela Figura 6

Figura 6 - Análise SWOT

\section{Na conquista do objetivo}

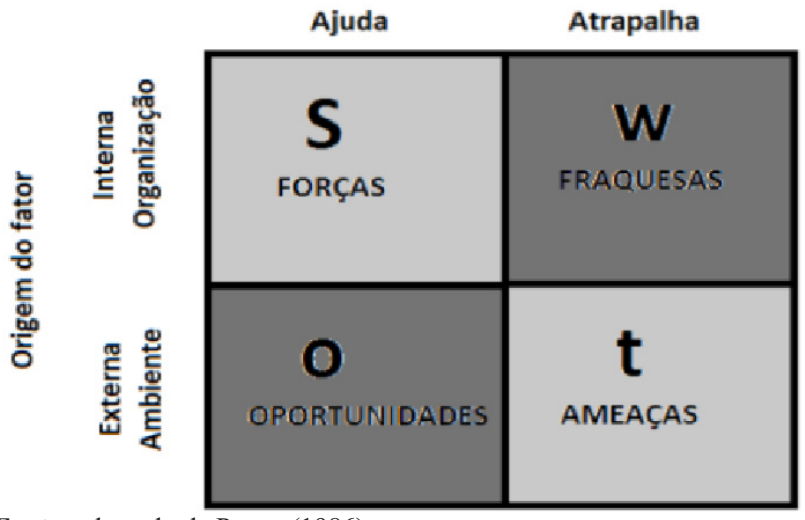

Fonte: adaptado de Porter (1986).

$\mathrm{O}$ ambiente interno representa algo que pode ser controlável pela empresa e entendê-lo é um fator primordial para que a empresa possa obter vantagem competitiva, potencializando os pontos que a diferenciam de seus concorrentes e eliminando, ou pelo menos minimizando, características que a desfavoreçam no mercado. Os aspectos que trazem vantagem competitiva frente a concorrência, podem ser classificados como forças da organização. Por outro lado, aquilo que é desvantagem em um ambiente empresarial, entende-se como uma fraqueza da companhia (MANTEGHI; ZOHRABI, 2011).

Para uma análise mais profunda do âmbito interno podese utilizar do modelo de estrutura $7 \mathrm{~S}$ da Mckinsey. Esta ferramenta é dividida em sete fatores necessários para que a empresa opere de maneira eficiente, entre eles estão: Estrutura, Sistemas, Estratégia, Habilidades, Pessoas, Estilo e Objetivos (KHAKBAZ; HAJIHEYDARI, 2015).

Em uma análise externa são estudados fatores como oportunidades e ameaças, características que uma empresa não consegue controlar. As oportunidades oferecem chances de suprir as necessidades que ainda não foram satisfeitas pelo mercado, gerando um aspecto positivo para a estratégia da organização. Por outro lado, as ameaças podem ser entendidas como uma forma de retardar o andamento dos objetivos da companhia, devido à concorrência e aos novo cenários do mercado (MANTEGHI; ZOHRABI, 2011).

Para avaliar o cenário externo, Lima Júnior et al. (2018) utilizaram da ferramenta análise PESTEL, investigando variáveis políticas, econômicas, sociais, tecnológicas, ambientais e legais que interferem ou impactem no negócio.

A análise SWOT pode ser utilizada em empresas de diferentes segmentos (LEVYA; RODRIGUEZ; FIERRO, 2016; LIAN, 2017; BORGES RAUPP et al., 2019).

A estratégia de desenvolvimento permite enxergar oportunidades que possam fortalecer os pontos fortes da empresa. O plano consiste em desenvolver atividades que sejam únicas no mercado, oferecendo produtos e serviços diferenciados dos demais concorrentes (PORTER, 1986). $\mathrm{Na}$ estratégia de crescimento evidencia-se que é preciso transcender os pontos fracos para atingir as oportunidades. Nesta situação, o ambiente está proporcionando situações favoráveis que podem transformar-se em oportunidades, quando usufrui-se da transformação de uma situação em que a empresa não domina ou estima-se que seja uma fraqueza (PORTER, 1986). Para eliminar ameaças, algumas vezes é necessário utilizar das forças que a companhia apresenta. A situação conhecida como estratégia de manutenção, permite a organização identificar ameaças do ambiente externo e utilizar de suas forças acumuladas ao longo dos anos, que possibilitam ao administrador, além de querer continuar sobrevivendo, também manter a sua posição conquistada até o momento (BORGES RAUPP et al., 2019). Por fim, a estratégia de sobrevivência deve ser adotada apenas quando o ambiente e a empresa estão em situação inadequada com muitas dificuldades ou quando apresentam péssimas perspectivas. Tal postura de sobrevivência é necessária pois a empresa precisa 
lidar com suas fraquezas e enfrentar as ameaças externas, normalmente parando investimentos e reduzindo ao máximo as despesas (BORGES RAUPP et al., 2019).

\subsection{Resultados}

\subsubsection{Missão, visão e valores}

A empresa não dispunha de uma filosofia e então foram feitos alguns encontros com o gestor e funcionários para definir a missão, visão e valores da companhia. Por meio de entrevistas abertas, da percepção que o autor deste trabalho obteve da empresa e da validação das respostas com o gestor, os resultados são mostrados no Quadro 2.

Quadro 2 - Descrição da Missão, Visão e Valores da empresa

\begin{tabular}{|c|l|}
\hline Missão & $\begin{array}{l}\text { Conectar o Brasil com serviços de transporte de } \\
\text { cargas, visando a sua eficiência, qualidade e a } \\
\text { sustentabilidade do negócio. }\end{array}$ \\
\hline Visão & $\begin{array}{l}\text { Ser a empresa reconhecida pela confiabilidade nos } \\
\text { transportes de cargas e por desenvolver o meio em } \\
\text { que atua. }\end{array}$ \\
\hline Valores & $\begin{array}{l}\text { Atender e entender as necessidades nossos parceiros } \\
\text { e clientes, ser objetivos nas ações para garantir a } \\
\text { agilidade, respeitar as pessoas e suas diferentes } \\
\text { maneiras de agir e pensar e utilizar de práticas } \\
\text { inovadora. }\end{array}$ \\
\hline
\end{tabular}

Fonte: Dados da pesquisa.

\subsubsection{Avaliação dos aspectos internos e externos à companhia e a análise SWOT}

Nesta seção foram levantados aspectos externos a empresa, identificando as oportunidades e as ameaças para o negócio pela avaliação de tópicos como: político, econômico, socioambiental, tecnológico e infra estrutural. Também foram apontados aspectos como as forças e fraquezas através de dados e visitas realizadas à companhia. A partir dessas informações foi construída a SWOT conforme o Quadro 3.

Quadro 3 - Análise SWOT

\begin{tabular}{|c|c|}
\hline Forças & Fraquezas \\
\hline $\begin{array}{l}\text { S1 Conhecimento do gestor } \\
\text { na área; } \\
\text { S2 Frota própria; } \\
\text { S3 Experiência no mercado; } \\
\text { S4 Localização da empresa. }\end{array}$ & $\begin{array}{l}\text { W1 Ausência de qualificação } \\
\text { profissional dos funcionários; } \\
\text { W2 Frota antiga; } \\
\text { W3 Falta de metodologia para } \\
\text { avaliar o frete; } \\
\text { W4 Ausência de tecnologia na } \\
\text { gestão da frota; } \\
\text { W5 Ausência de marketing } \\
\text { para novos clientes. }\end{array}$ \\
\hline Oportunidades & Ameaças \\
\hline $\begin{array}{l}\text { O1 PIB da região onde está } \\
\text { inserida a empresa; } \\
\text { O2 Representação do } \\
\text { transporte rodoviário no setor } \\
\text { logístico; } \\
\text { O3 Uso da tecnóloga no } \\
\text { auxílio da gestão de frotas; } \\
\text { O4 Concentração de rodovias } \\
\text { na região; } \\
\text { O5 Flexibilidade para as } \\
\text { entregas. } \\
\text { O6 Novas tecnologias de } \\
\text { máquinas para beneficiamento }\end{array}$ & $\begin{array}{l}\text { A1 Nova legislação da tabela } \\
\text { do frete mínimo; } \\
\text { A2 Instabilidade econômica } \\
\text { do país; } \\
\text { A3 Custos de aquisição e } \\
\text { manutenção do caminhão; } \\
\text { A4 Preço do combustível; } \\
\text { A5 Segurança no transporte } \\
\text { de cargas; } \\
\text { A6 Condições de } \\
\text { infraestrutura. }\end{array}$ \\
\hline
\end{tabular}

Fonte: Dados da pesquisa.
Em relação aos aspectos externos, uma parte dos dados foram coletados de estudos realizados pela Confederação Nacional dos Transportes (CNT) e deles foi possível extrair diversas informações. A primeira oportunidade, vista por meio dos dados obtidos pelos relatórios da CNT, está relacionada com a representatividade do transporte rodoviário no setor logístico, cerca de $68,8 \%$ de todo investimento do governo federal para o transporte em geral são alocados a esse modal e $63 \%$ da logística brasileira é feita por rodovias. Outro fator muito importante é a representatividade da região sudeste no Produto Interno Bruto (PIB) da economia do país e dos transportes, valores em torno de $52,4 \%$ e $59,6 \%$ respectivamente. Outros aspectos relevantes que foram considerados como oportunidades, um está relacionado com a flexibilidade das entregas por esse modal e o segundo a grande concentração de rodovias na região onde a empresa está situada. (CNT, 2018b)

A oportunidade de número três $(\mathrm{O} 3)$ da análise SWOT é referente a utilização de novas tecnologias para o auxílio da gestão de frotas e cálculo de fretes que foi verificado na Feira Nacional dos Transportadores de Cargas (FENATRAN). Foram localizadas diversas empresas que estão atuando no setor e trazendo um portfólio enorme de ferramentas que vão desde dashbords com informações sobre o desempenho financeiro da companhia até sistemas instalados nos próprios caminhões e carretas para verificar consumo de combustível, desgaste dos equipamentos e pressões dos pneus. Em entrevista com um funcionário de empresa que fabrica máquinas para beneficiamento de alimentos, foi identificado novas tecnologias neste setor e, também, foi considerada uma oportunidade porque é o tipo de carga que a Transportadora Bilatto tem experiência em transportar.

Em relação as ameaças, foram coletadas informações dos relatórios da CNT e neles foram identificadas questões como: instabilidade econômica do setor de transportes e do país, condições de infraestrutura, segurança do transporte e preços do combustível. O PIB do transporte cresceu 1,7\% no ano de 2018, mas nos três últimos semestres o setor acumulou uma perda de $1,2 \%$. O PIB da economia brasileira cresceu $0,3 \%$ até o final do segundo semestre desse ano de 2019, porém ainda opera muito abaixo do período pré-crise, é necessário crescer algo em torno de 7\% para atingir os níveis entre os anos de 2013 e 2014. A grande variação no preço dos combustíveis também é algo que incomoda os transportadores, essa é uma questão bem complexa onde estão envolvidos aspectos como o dólar, cotação internacional do barril de petróleo, preço do biodiesel e entre outros. (CNT, 2019a)

Foi avaliado também as condições de infraestrutura que o país oferece, dos $1.720 .700 \mathrm{~km}$ de rodovias apenas 213.453 $\mathrm{km}(12,4 \%)$ são pavimentados. Segundo relatório produzido pela CNT, a densidade de rodovias pavimentadas é igual a $25,1 \mathrm{Km}$ pavimentas / $1000 \mathrm{Km} 2$ de território, valor muito 
baixo comparado a países como Estados Unidos $(437,8)$, China (421,6), México (70,0), Rússia $(54,6)$ e Uruguai $(43,9)$. Levantou-se também que $57 \%$ das rodovias pavimentadas foram classificadas como regular, ruim ou péssima. Os custos com acidentes são mais altos que os investimentos feitos pelo governo em rodovias e os roubos de cargas representaram uma perda de R\$ 1,5 bilhão de reais no ano de 2017. (CNT, 2019b)

Após encontrar as oportunidades e as ameaças que estão sujeitas a Transportadora Bilatto, foi analisado os aspectos internos a companhia. Os pontos fortes mapeados na Análise SWOT, estão relacionados com a experiência de mercado, conhecimento do gestor do setor de transportes como um todo, frota própria e a localização da empresa.

A experiência de mercado foi adquirida ao longo dos cinquenta anos de atuação da empresa, principalmente transportando para o setor de máquinas para beneficiamento de alimentos. O gestor apresenta grande conhecimento tanto na área técnica, como funcionamento e manutenção dos caminhões, quanto nos negócios que envolvem a companhia.

A questão sobre ter uma frota própria é um diferencial que a companhia apresenta, pois, muitas transportadoras concorrentes não possuem caminhão e dependem da contratação de terceiros para realizar as entregas. Dessa forma, tal aspecto acaba sendo importante para a empresa por dois motivos: é possível fazer uma avaliação do custo e do lucro para o transporte de uma carga e entender se é mais vantajoso contratar um terceiro ou mandar um caminhão próprio com um funcionário; e o outro fator relevante é devido a implementação da tabela do frete mínimo na qual não se pode contratar um terceiro e pagar um preço abaixo do especificado pela tabela, o que dificulta principalmente sobre a questão da lucratividade da empresa.

Como último fator analisado na SWOT, foram listadas as seguintes fraquezas: ausência de qualificação dos funcionários, frota antiga, ausência de marketing para novos clientes e tecnologias para gestão de frota e falta de exatidão no cálculo do frete. Em relação ao primeiro tópico, grande parte das atividades administrativas da empresa é concentrada em apenas uma pessoa e quando ela está ausente, assuntos como cotação de frete, por exemplo, acaba levando um certo tempo pra ser repassada ao cliente que solicitou e isso pode gerar uma desistência pela necessidade de urgência para contratar o transporte.

Sobre a tecnologia na área de gestão de frotas e cálculo de frete é um assunto que já foi abordado anteriormente e que a transportadora ainda não possui tal recurso. Pelo fato de a empresa não apresentar atualmente um poder de compra suficiente para adquirir um caminhão, a companhia opera com uma frota que apresenta uma certa idade, deixando de obter caminhões com tecnologias mais avançadas e diminuir gastos com manutenção.

\subsubsection{Identificação das estratégias via análise SWOT}

Após a construção da SWOT a partir das análises do ambiente externo e dos aspectos internos, foram mapeadas quatro estratégias conforme o Quadro 4.

Quadro 4 - Estratégias estratificadas da SWOT

\begin{tabular}{|l|l|}
\hline \multicolumn{1}{|c|}{ Desenvolvimento } & \multicolumn{1}{|c|}{ Crescimento } \\
\hline $\begin{array}{l}\text { 1. Expandir os negócios e } \\
\text { alcançar novos clientes através } \\
\text { da experiência no mercado } \\
\text { com o auxílio da tecnologia } \\
\text { para gestão da frota; }\end{array}$ & $\begin{array}{l}\text { 2. Qualificar os funcionários e } \\
\text { utilizar de novas tecnologias } \\
\text { para que se tenha uma tomada } \\
\text { de decisão mais assertiva em } \\
\text { gelaço as avaliações de fretes, } \\
\text { das melhores rotas. Com isso } \\
\text { espera-se adquirir a confiança } \\
\text { de novos clientes com } \\
\text { redução de custos e aumento } \\
\text { da eficiência e qualidade das } \\
\text { entregas; }\end{array}$ \\
\hline \multicolumn{1}{|c|}{ Manutenção } & Sobrevivência \\
\hline $\begin{array}{l}\text { 3. Utilizar da vantagem da } \\
\text { frota própria e da experiência } \\
\text { do mercado para superar } \\
\text { obstáculos como a tabela } \\
\text { do frete mínimo e os altos } \\
\text { custos que está sujeita uma } \\
\text { transportadora; }\end{array}$ & $\begin{array}{l}\text { que operemos de maneira } \\
\text { que os custos da frota não } \\
\text { interfiram no valor do frete } \\
\text { e entreguemos com a maior } \\
\text { segurança. }\end{array}$ \\
\hline
\end{tabular}

Fonte: Dados da pesquisa.

\subsubsection{Definição da estratégia e construção do mapa estratégico}

Por meio de reuniões realizadas com o gestor e entendida a situação que a empresa se encontra, decidiu-se optar pela estratégia de crescimento pois há uma necessidade de utilizar da gama de oportunidades que o ambiente apresenta para eliminar algumas fraquezas que a companhia demonstra. A partir desta estratégia foi construído o mapa estratégico da Transportadora Bilatto Ltda. com os objetivos a curto prazo para cada perspectiva e interligados pela relação de causa e efeito.

Representado pela Figura 7, o mapa reproduz uma visão geral dos caminhos para cumprir a estratégia a longo prazo definida no passo anterior. Na perspectiva de inovação e aprendizado ficou estabelecido a necessidade do comprometimento da equipe e desenvolvimento dos funcionários para estarem alinhados e motivados com a filosofia e os objetivos estabelecidos pela empresa. Assim, a equipe estará preparada para desenvolver novas soluções tecnológicas e/ou computacionais que auxiliem a companhia tornar-se mais competitiva no mercado. 
Figura 7 - Mapa estratégico Transportadora Bilatto

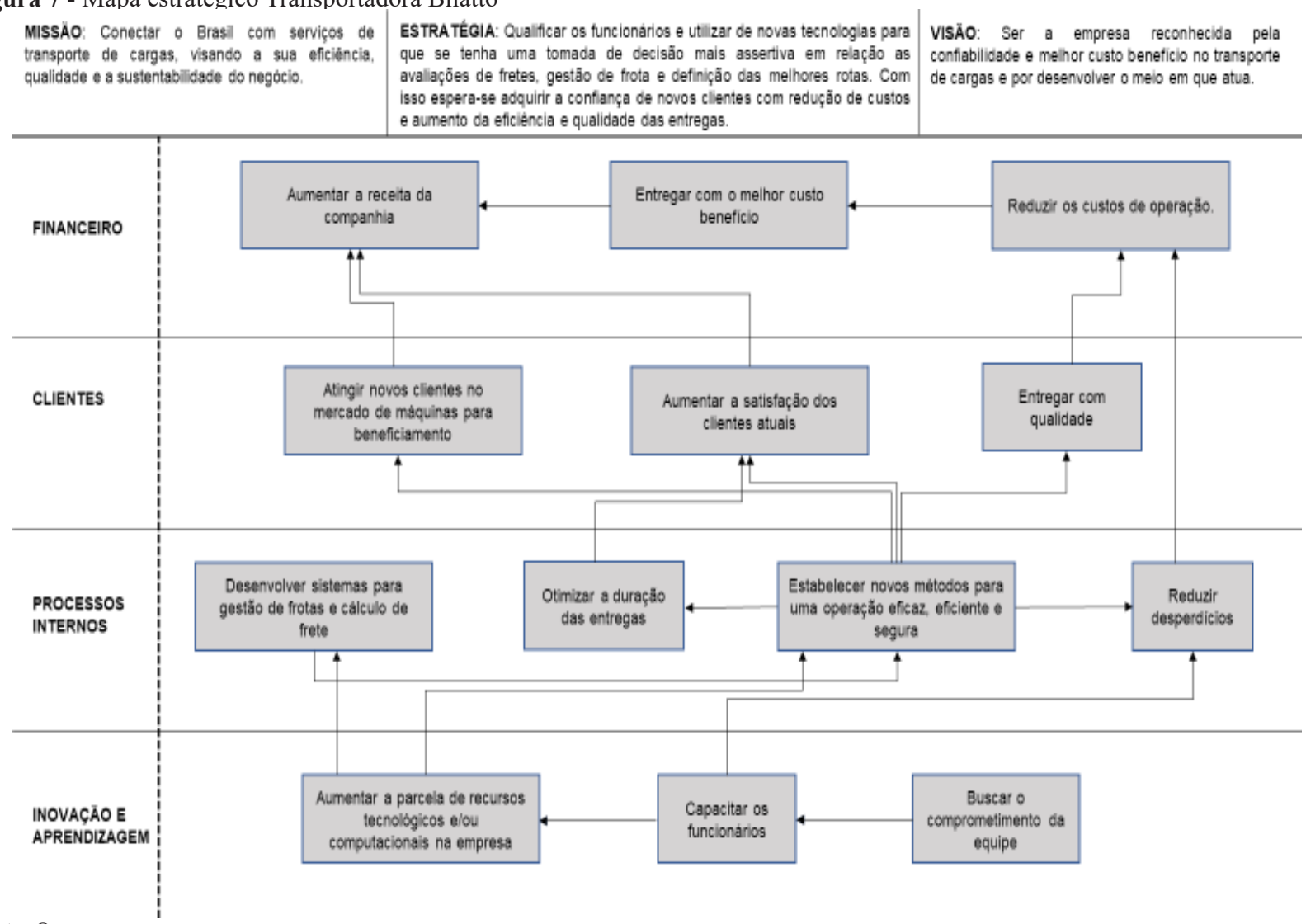

Fonte: Os autores.

A partir dos objetivos definidos na perspectiva de inovação e aprendizado, em processos internos foi possível focar em assuntos que estivessem relacionados com novos métodos para a empresa gerir a frota, calcular fretes, otimizar a duração das entregas e operar de maneira eficiente e segura, além de reduzir os diversos desperdícios com itens que estão relacionados com a quilometragem rodada pelo caminhão (combustível, pneus, lubrificantes, lavagem, depreciação e entre outros).

Por meio do desenvolvimento de novos sistemas e métodos, definidos em processos internos, foi viável construir objetivos para a perspectiva de clientes que estivessem direcionados para a expansão de mercado com a aderência de novos clientes, aumentando a satisfação dos atuais e entregar com qualidade sem nenhuma avaria relacionada ao transporte.

A quarta perspectiva, a financeira, por fim traduziu-se todos os objetivos definidos em redução de custos, entrega com melhor custo benefício e o aumento da receita da companhia. A redução dos custos de operação está relacionada com os custos variáveis (consumo de combustível, desgaste de componentes e manutenção dos caminhões) e fixos da empresa (salários, impostos e contas diversas). Para desenvolver valores de fretes competitivos e compatíveis ao mercado, é necessário desenvolver objetivos relacionados ao custo-benefício oferecidos aos clientes. E por fim, com o aumento da receita da empresa é possível reinvestir em novas aquisições para o crescimento e expansão da Transportadora.

\subsubsection{Construção dos indicadores e definição do scorecard}

O Quadro 5 apresenta os quatorze indicadores da Transportadora Bilatto e as fórmulas para calculá-los traduzindo em números os treze objetivos teóricos definidos no mapa estratégico.

Quadro 5 - Indicadores da Transportadora Bilatto Ltda

\begin{tabular}{|c|c|c|c|}
\hline Perspectiva & Objetivo & Indicador & Fórmula \\
\hline \multirow{4}{*}{ Financeiro } & \multirow[b]{2}{*}{ Reduzir custos de operação } & Custo Fixo & Custo fixo mensal da empresa \\
\hline & & Custo variável por caminhão & $\begin{array}{l}\text { (Todos os custos relacionados ao } \mathrm{Km} \\
\text { rodado } /(\mathrm{Km} \text { rodado })\end{array}$ \\
\hline & $\begin{array}{l}\text { Entregar com o melhor custo } \\
\text { benefício }\end{array}$ & $\begin{array}{l}\text { Preço de frete médio por Quilômetro } \\
\text { rodado }\end{array}$ & (Valor médio de frete $) /(\mathrm{km}$ rodado $)$ \\
\hline & Aumentar a receita da companhia & Faturamento total da empresa & Lucro Líquido \\
\hline
\end{tabular}




\begin{tabular}{|c|c|c|c|}
\hline Perspectiva & Objetivo & Indicador & Fórmula \\
\hline \multirow{3}{*}{ Clientes } & $\begin{array}{l}\text { Atingir novos clientes no mercado } \\
\text { de máquinas para beneficiamento }\end{array}$ & Índice de novos clientes por mês & $\begin{array}{l}\text { (Qtde de clientes do período atual) / } \\
\text { (Qtde de clientes do último período) }\end{array}$ \\
\hline & Aumentar a satisfação dos clientes & Nível de satisfação dos clientes & $\begin{array}{l}\text { Pontuação de satisfação após as } \\
\text { entregas }\end{array}$ \\
\hline & Entregar com qualidade & Avarias de cargas & Custo total da carga danificada \\
\hline \multirow{6}{*}{$\begin{array}{l}\text { Processos } \\
\text { Internos }\end{array}$} & $\begin{array}{l}\text { Desenvolver sistemas para gestão de } \\
\text { frota e cálculo de frete }\end{array}$ & $\begin{array}{l}\text { Comparativo entre custo estimado e } \\
\text { custo real }\end{array}$ & (Custo estimado) / (Custo Real) \\
\hline & \multirow[b]{2}{*}{$\begin{array}{l}\text { Estabelecer métodos para uma } \\
\text { operação eficaz, eficiente e segura }\end{array}$} & Número de acidentes & Quantidade de acidentes \\
\hline & & $\begin{array}{l}\text { Tempo médio de entrega de } \\
\text { orçamentos para os clientes }\end{array}$ & $\begin{array}{l}\text { Tempo médio entre uma ordem de } \\
\text { orçamento até o recebimento pelo } \\
\text { cliente }\end{array}$ \\
\hline & \multirow[b]{2}{*}{ Otimizar a duração das entregas } & $\begin{array}{l}\text { Índice de tempo médio de entregas } \\
\text { de cargas }\end{array}$ & $\begin{array}{l}\text { (tempo de entrega) / (prazo } \\
\text { estimado) }\end{array}$ \\
\hline & & $\begin{array}{l}\text { Tempo médio de ociosidade dos } \\
\text { caminhões }\end{array}$ & $\begin{array}{l}\text { (tempo parado no pátio, carga e } \\
\text { descarga) / (tempo disponível no } \\
\text { mês) }\end{array}$ \\
\hline & Reduzir desperdícios & Custo variável & $\begin{array}{l}\text { (Todos os custos relacionados a } \mathrm{Km} \\
\text { rodado } /(\mathrm{Km} \text { rodado })\end{array}$ \\
\hline \multirow{3}{*}{$\begin{array}{l}\text { Inovação e } \\
\text { Aprendizagem }\end{array}$} & $\begin{array}{l}\text { Aumentar a parcela de recursos } \\
\text { tecnológicos e/ou computacionais na } \\
\text { empresa }\end{array}$ & $\begin{array}{l}\text { Índice dos recursos utilizados no } \\
\text { Mês atual comparado com mês } \\
\text { anterior }\end{array}$ & $\begin{array}{l}\text { (recursos do mês atual) / (recursos } \\
\text { do mês anterior) }\end{array}$ \\
\hline & Capacitar os funcionários & Número de treinamento & $\begin{array}{l}\text { Quantidade de treinamentos } \\
\text { implementados }\end{array}$ \\
\hline & $\begin{array}{l}\text { Buscar o comprometimento da } \\
\text { equipe }\end{array}$ & Número de sugestões implementadas & $\begin{array}{l}\text { Quantidade de sugestões } \\
\text { implementadas }\end{array}$ \\
\hline
\end{tabular}

Fonte: Os autores.

A Figura 8 ilustra o scorecard desenvolvido para a Transportadora Bilatto LTDA e foi elaborado no Excel a partir da vinculação com o banco de dados criado para alimentar esses indicadores.

Figura 8 - Scorecard Transportadora Bilatto Ltda

\begin{tabular}{|c|c|c|c|c|c|c|c|c|c|}
\hline & & & & & Tempo M & io de entre & ja de cargas & & \\
\hline Caminhão & $\begin{array}{c}\text { Preço de } \\
\text { frete }(\mathrm{R} \$ / \mathrm{Km})\end{array}$ & $\begin{array}{c}\text { Custo } \\
\text { Variável } \\
\text { (R\$/Km) }\end{array}$ & $\begin{array}{c}\text { Lucro } \\
\text { Líquido (R\$) }\end{array}$ & $\begin{array}{l}\text { Tempo } \\
\text { Ocioso } \\
\text { (horas) }\end{array}$ & $\begin{array}{c}\text { Dentro do } \\
\text { Prazo } \\
\text { (Dias) }\end{array}$ & $\begin{array}{c}\text { No Prazo } \\
\text { (Qtde) }\end{array}$ & $\begin{array}{c}\text { Fora do } \\
\text { Prazo (Dias) }\end{array}$ & $\begin{array}{c}\text { Satisfação } \\
\text { dos clientes } \\
\text { (Pontos) }\end{array}$ & \begin{tabular}{|c} 
Indice \\
Custo \\
Estimado \\
x Real
\end{tabular} \\
\hline 1 & & & & & & & & & \\
\hline 2 & & & & & & & & & \\
\hline 3 & & & & & & & & & \\
\hline 4 & & & & & & & & & \\
\hline 5 & & & & & & & & & \\
\hline Terceiro & & & & N/A & N/A & N/A & N/A & & \\
\hline Média Geral & & & & & & & & & \\
\hline
\end{tabular}

\begin{tabular}{|l|l|}
\hline \multicolumn{2}{|c|}{ Custo Fixo (R\$/Mês) } \\
\hline Despesas & Valores \\
\hline Salário & \\
\hline Seguro & \\
\hline Licenciamento & \\
\hline Imposto Simples & \\
\hline FGTS & \\
\hline GPS & \\
\hline IPTU & \\
\hline OUTROS & \\
\hline Média Geral & \\
\hline
\end{tabular}

\begin{tabular}{|l|l|}
\hline Índice de novos clientes \\
\hline Mês & Clientes \\
\hline Outubro & \\
\hline Novembro & \\
\hline Índice & \\
\hline
\end{tabular}

\begin{tabular}{|l|l|}
\hline \multicolumn{2}{|c|}{ Aprendizado e Inovação } \\
\hline Treinamentos & \\
\hline Novos recursos & \\
\hline Número de sugestões & \\
\hline
\end{tabular}

\begin{tabular}{|l|l|}
\hline \multicolumn{2}{|c|}{ Número de Acidentes } \\
\hline NÃO & \\
\hline AVARIAS CONCERTÁVEIS & \\
\hline PERDA TOTAL & \\
\hline S/ AFASTAMENTO & \\
\hline C/ AFASTAMENTO & \\
\hline FATALIDADE & \\
\hline Total de acidentes & \\
\hline
\end{tabular}

\section{Entrega de orçamentos}

Tempo médio (min)

Fonte: Os autores. 


\subsubsection{Acompanhamento dos indicadores e definição das metas}

Após a criação dos indicadores, passou-se a coletar os dados da empresa dos meses de setembro e outubro de 2019. Ao ser gerado os valores para cada um dos indicadores, a visão sobre os números da companhia foi ficando mais claros tanto para o autor deste trabalho quanto para o gestor e, dessa forma, foi viável estimar as metas.

\subsection{Análise dos Resultados}

A criação dos indicadores pela metodologia BSC mostrouse adequado para a Transportadora Bilatto LTDA pois foi possível entender suas estratégias por meio da definição da filosofia da empresa e da avaliação de questões internas e dos aspectos políticos, econômicos, socioambientais, tecnológicos e infra estrutural do setor de transporte de carga. Essas questões iniciais foram importantes para mapear as dificuldades e necessidades que a companhia teria de enfrentar e quais tópicos eram considerados como vantagens para enfrentar a concorrência. Dessa forma foi viável desdobrar objetivos que conduzissem a empresa na direção da estratégia definida e torná-la mais assertiva na construção dos indicadores, que é uma maneira de mostrar se o caminho para o destino desejado está sendo cumprido.

O gestor da empresa avaliou de forma positiva o estudo pois passou a enxergar melhor o cenário que a transportadora estava inserida e visualizou toda sua estratégia, desde a concepção da filosofia, até entender qual o destino que a companhia deveria se direcionar para superar a crise que abalou o setor e voltar a crescer no mercado. Outro ponto importante ressaltado foi a facilidade de entender o desempenho da companhia por meio do scorecard e o suporte que esses indicadores podem fornecer para tomar decisões mais claras.

Considerou-se satisfatória a relação de causa e efeito do mapa estratégico. Acredita-se que o fato de a empresa ser pequena e o gestor estar sempre acompanhando o processo de desenvolvimento do trabalho, auxiliou na criação de um mapa estratégico robusto, que representou as relações de cada objetivo das diferentes perspectivas.

Pelo motivo da empresa não dispor de um banco de dados eficiente, houve grande dificuldade para coletar os dados e verificar o desempenho do scorecard, o que também acabou gerando metas não tão assertivas como era esperado. O gestor propôs melhorar o método de armazenamento de dados, com a finalidade de obter números mais confiáveis, para melhor avaliação do desempenho, além da necessidade de um período maior que dois meses para definir as metas de forma mais exata.

O scorecard foi criado em uma tabela do Excel na qual é atualizada automaticamente conforme adiciona-se novos dados que alimentam os indicadores, porém como já foi descrito, é necessário melhorar o método de coleta de informações. Após realizar esse último ajuste, foi sugerido transformar esses indicadores em dashboards para que o gestor tenha uma visão mais clara e limpa do desempenho da empresa.

\section{Conclusão}

Realizaram-se análises do mercado que a transportadora estava inserida, obtendo-se resultados com diversas oportunidades na área, mas também foram levantados tópicos que pudessem ameaçar o andamento das estratégias. A verificação dos aspectos relacionados ao ambiente da empresa foi iniciada com a definição da filosofia, como a missão, visão e valores, e depois foram analisadas suas forças e fraquezas para completar a análise SWOT.

Foi definida a estratégia de acordo com as análises realizadas e o destino que o gestor gostaria de levar a companhia. Com base nisso, foi escolhida a estratégia que eliminasse algumas fraquezas a partir das oportunidades que o mercado de transporte poderia oferecer. A partir daí, foi criado o mapa estratégico da empresa com os objetivos separados por cada uma das perspectivas do BSC interligadas por meio da relação de causa e efeito.

Baseado no que foi desenhado como estratégia para a companhia, foram desenvolvidos os indicadores como forma de medir e avaliar o andamento dos objetivos. O resultado do scorecard foi acompanhado com uma base de dados referente aos meses de setembro e outubro, com a finalidade de visualizar seu funcionamento e identificar melhorias a serem realizadas.

De forma geral, a implementação dos indicadores de performance desenvolvidos para uma empresa transportadora de carga a partir da metodologia BSC foi executada adequadamente, o gestor avaliou de forma satisfatória a elaboração do planejamento estratégico e a nova maneira de visualizar o desempenho da companhia.

\section{Referências}

BHAGWAT, R.; SHARMA, M. K. Performance measurement of supply chain management: a balanced scorecard approach. Comp. Ind. Engin., v.53, n.1, p.43-62, 2007. doi: http://doi. org/10.1016/j.cie.2007.04.001.

BORGES RAUPP, E. et al. Gestão de resíduos e a análise SWOT: Estudo de caso em uma organização de maquinaria agrícola. Scie. Ind., v.6, n.3, p.17-26, 2019. doi: http://doi. org/10.18226/23185279.v6iss3p17.

CAMBOIM, V. S. da C. et al. Diagnóstico para implantação do balanced scorecard: um estudo de caso em uma empresa de pequeno porte. Rebrae, v.4, n.3, p.245, 2017. doi: http://doi. org/10.7213/rebrae.v4i3.13694.

CNT. PIB do transporte avança 2,2\% em 2018, corroborando cenário de recuperação gradual. Confederação Nacional do Transporte - Economia em foco, p. 1-6, 2018a. Disponível em: <http://repositorio.itl.org.br/jspui/handle/123456789/295>. Acesso em: 16 abr. 2019.

CNT. Setor de transporte ainda opera com volume de serviços abaixo do nível pré-recessão. Confederação Nacional do Transporte - Conjuntura do Transporte. 2009. Disponível em: 
$<$ http://repositorio.itl.org.br/jspui/handle/123456789/311>. Acesso em: 29 jul. 2019.

CNT. Por que o preço dos combustíveis cai mais nas refinarias do que nas bombas? Confederação Nacional do Transporte Economia em Foco, p. 11, 2019a.

CNT. Desempenho econômico: desempenho da economia brasileira e do setor de transporte. Confederação Nacional do Transporte - Transporte em números. Disponível em: <http:// repositorio.itl.org.br/jspui/handle/123456789/312>. Acesso em: 22 set. 2019.

CUI, J.; ALLAN, A.; LIN, D. SWOT analysis and development strategies for underground pedestrian systems. Tunnelling and Underground Space Technology, v. 87, p.127-133, 2019. doi: http://doi.org/10.1016/j.tust.2018.12.023.

DAVID, O. Performance management: a framework for management control systems research. Management Accounting Res., v.10, n.4, p.363-382, 1999.

DE ANDRADE GUERRA, J. B. S. O. et al. A proposal of a Balanced Scorecard for an environmental education program at universities. J. Cleaner Production, v.172, p.1674-1690, 2018. doi: http://doi.org/10.1016/j.jclepro.2016.11.179.

FERNANDES, I. G. M. et al. Planejamento estratégico: análise SWOT. Rev. Conexão Eletr., v.8, n.1, p.1464-1473, 2015.

GRIGOROUDIS, E.; ORFANOUDAKI, E.; ZOPOUNIDIS, C. Strategic performance measurement in a healthcare organisation: a multiple criteria approach based on balanced scorecard. Omega, v.40, n.1, p.104-119, 2012. doi: http://doi.org/10.1016/j. omega.2011.04.001.

HUANG, H. C. Designing a knowledge-based system for strategic planning: A balanced scorecard perspective. Expert Systems with Applications, v. 36, n. 1, p. 209-218, 2009. doi: http://doi.org/10.1016/j.eswa.2007.09.046.

JAFARI, M.; SHAHANAGHI, K.; TOOTOONI, M. Developing a Robust Strategy Map in Balanced Scorecard Model Using Scenario Planning. Mathematical Problems in Engineering, v. 2015, 2015. doi: http://doi.org/10.1155/2015/102606.

KAPLAN, R. S.; NORTON, D. P. The Balanced Scorecard Measures That Drive Performance Harvard Business Review , 1992. Disponível em: <https://encurtador.com.br/mpsL8>. Acesso em: 19 abril 2019.

KHAKBAZ, S. B.; HAJIHEYDARI, N. Proposing a basic methodology for developing balanced scorecard by system dynamics approach. Kybernetes, v. 44, n.6/7, p.1049-1066, 2015. doi: http://doi.org/10.1108/K-12-2014-0287.

KHOMBA, J. K. Conceptualisation of the Balanced Scorecard (BSC) model: A critical review on its validity in Africa. Int. J. Com. Manag., v.25, n.4, p.424-441, 2015. doi: http://doi. org/10.1108/IJCoMA-12-2012-0077.

LEVYA, E.A.L.; RODRIGUEZ, G.C.; FIERRO, I.S. Strategic plan for a processed foods company using megaplanning and balanced scorecard. Performance Improvement Quarterly, v.28, n. 4, p. 27-54, 2016. doi: http://doi.org/10.1002/piq.21208.

LIAN, Z. Research on development strategy of automobile reverse logistics based on SWOT analysis. Procedia Engineering, v.174, p.324-330, 2017. doi: http://doi.org/10.1016/j. proeng.2017.01.147.

LIMA JÚNIOR, C. G. et al. Implantação do balanced scorecard em uma indústria de cerâmica vermelha. Rev Expressão Católica, v.7, n.2, p.72, 2018. doi: http://doi.org/10.25190/rec.v7i2.2235.

LOBO, E.; VALENTE, A.M. Brazilian cargo road transportation infrastructure, 2015. doi: http://doi.org/10.4025/actascitechnol. v36i3.18843.

MANTEGHI, N.; ZOHRABI, A. A proposed comprehensive framework for formulating strategy: A hybrid of balanced scorecard, SWOT analysis, porter's generic strategies and fuzzy quality function deployment. Procedia - Soc. Behavioral Scie., v.15, p.2068-2073, 2011. doi: http://doi.org/10.1016/j. sbspro.2011.04.055.

NACHTMANN, H. et al. Development of a balanced scorecard for flight line maintenance activities. J. Quality Maintenance Eng., v.21, n.4, p.436-455, 2015. doi: http://doi.org/10.1108/ JQME-07-2012-0023.

OLVE, N.; ROY, J.; WETTER, M. Performance drivers: a practical guide to using the balanced scorecard. Work Study, v.49, n. 1, 2000. doi: http://doi.org/10.1108/ws.2000.07949aae.004.

SADOWSKA, B.; LULEK, A. Logistics costs and balanced scorecard in business management. Ekonomiczne Problemy Usług, v.120, n.890, p.91-104, 2016. doi: http://doi.org/10.18276/ epu.2015.120-07.

SILVA, A. A. da et al. A Utilização da Matriz Swot como Ferramenta Estratégica - um estudo de caso em uma escola de idioma de São Paulo. In: SEGeT - SIMPÓSIO DE EXCELÊNCIA EM GESTÃO E TECNOLOGIA, p.11, 2011. Disponível em: $<$ https://encurtador.com.br/lLMT5>. Acesso em: 5 maio 2019.

TRIPP, D. Action research: a methodological introduction. p.443-466, 2005. doi: http://doi.org/10.1590/S151797022005000300009 .

VACCARI, N. Proposta e aplicação de um modelo de desdobramento da estratégia com base no Balanced Scorecard: o caso de uma empresa de transporte de carga e logística. 2006. Disponível em: < https://hdl.handle.net/10923/1228>. 11/05/2019

WIERSMA, E. For which purposes do managers use Balanced Scorecards?. An empirical study. Manag. Accounting Res., v.20, n.4, p.239-251, 2009. doi: http://doi.org/10.1016/j. mar.2009.06.001.

KAPLAN, R.S.; NORTON, D. P. The execution premium: linking strategy to operations for competitive Advantage Harvard Business Review, 2008.

PORTER, M.S. Estratégia competitiva: análise de indústrias e da concorrência. Rio de Janeiro: Campus, 1986. 